\title{
LIGNOCELLULOSIC BIO-REFINERY DOWNSTREAM PRODUCTS IN FUTURE PACKAGING APPLICATIONS
}

\author{
Igor Karlovits (i) \\ Pulp and Paper Institute, Ljubljana, Slovenia
}

\begin{abstract}
The concept of efficient utilisation of renewable bio-based materials (biomass feedstock) is the driving force in the green transformation to a more sustainable and circular society. Biorefineries or biochemical platforms convert and utilise different sources of biomass into fuels and other beneficial derivates like fibres and other bio-based chemicals. These can be used as building blocks for many potentially useful applications. In this review, we shall describe the current state of the art and trends in the conversion of lignocellulosic feedstock into materials which can be primarily used in packaging applications. The three main constituents (cellulose, hemicellulose and lignin) are being re-engineered into new products with higher added value. The main goal of all these downstream products is that they do not compete with animal feed and food applications. The main downstream products of different kind of transformations are different natural fibres which can be further processed into micro or nano fibrillated state and used for a broad application of fields from ink, adhesive and packaging materials. Also, fibres and its derivates can be bonded successfully into bio-composites or fibre-based foams applications for the protective packaging applications. Hemicellulose, as a second most abundant component, has been researched for applications in adhesives and paper and paperboard coatings. Lignin which is currently utilised as an energy source for the paper industry, has been recently actively researched. Lignin-based biopolymers have a potential to be used in many different applications from additives in the barrier coatings on the packaging to active packaging and even as lignin-based foams. All these applications are currently in the development stages and cover niche market segments, but are expected to grow and to be used in future markets.
\end{abstract}

Keywords: biorefinery, fibres, lignin, packaging, fibre-based foams

\section{INTRODUCTION}

Packaging with its multiple functions and sometimes conflicting requirements throughout the life cycle of a product makes a vital building block for all societies from the old ages to contemporary modern societies. With steady continual grow at $2.8 \%$ and soaring market values of $\$ 1.05$ trillion in 2024 (from $\$ 917$ billion in 2020) according to Smither Pira study (Pira, 2019) packaging market is significant for all countries. This trend of the growing market is similar to all continents, but trends in structure and future perspectives differ for continents. The E.U.S the recent administrative and legislative decisions like the Directive 2008/98/EC on waste and connected specific Directives (E.U., 2008), Directive 94/62/EC on packaging and packaging waste (E.U., 1994) and the most recent Green Deal (E.U., 2020) puts the E.U. trailing to be the first climate-neutral continent. The European Green Deal is an action plan to:

- boost the efficient use of resources by moving to a clean, circular economy

- restore biodiversity and cut pollution

A part of the European Green Deal is also the new Circular Economy Action Plan (E.U., 2020) which presents new initiatives along the entire life cycle of products in modernising the E.U. economy while protecting the environment. Inside this Action plan for packaging, there are several ways the E.U. wants to tackle the packaging waste problems. Single-use products will be phased out wherever possible and replaced by durable products for multiple uses. New legislative initiatives on reuse to substitute singleuse packaging, tableware and cutlery by reusable products in food services, as well as targets for reducing packaging waste, will be proposed. Measures will be introduced for waste prevention and reduction, increasing recycled content, minimising waste exports outside E.U. Another action plan the Farm to Fork targets the agricultural sector where more natural production and resource efficiency is promoted with an emphasis on sustainable production. If we take a step back and rethink these goals and which resource is renewable and also has some additional benefits, the solution is the lignocellulosic biomass. Photosynthesis removes carbon dioxide from the air to produce sugars. A large part of carbon is built into these sugars, and the rest of the oxygen goes into the air. The sugar is converted into other organic compounds that are useful to the plant. A surprisingly wide range of compounds is produced, including 
starches, fats, proteins, and many other classes of molecules. However, a very high percentage of the sugar is simply converted into cellulose - or in the case of woody plants, cellulose and lignin. Because all biomass consists of carbon-rich compounds - and the carbon in these compounds originated as atmospheric $\mathrm{CO}_{2}$ captured by green plants to create sugar - forests can be viewed as a significant carbon sink. A "carbon sink" is anything that absorbs large amounts of carbon dioxide from the atmosphere, retaining the carbon in one form or another (Bouchard, 2018). One of the major consumers of wood is, of course, the pulp and paper industry, with over $40 \%$ of all industrially traded wood (W.W.F., 2020). Other consumers are mainly (industrial Roundwood, pellets, sawn wood, and wood-based panels (F.A.O., 2018). These sectors are mainly mechanically processing the wood and retaining the sunk sugars carbon and fibres in the structure. So, the pulp and paper industry have a long tradition in chemically modifying the lignocellulosic biomass, it has some side streams which have also been tried in the past to be utilised, but until now the market product was pulp and natural fibre which are converted to paper and boards. There are other industrial facilities which are using lignocellulosic biomass - not wood-based, but another kind of crops and agro-residues to produce energy or animal feedstock. So, the concept of these facilities were the founding stones of the biorefineries. The bioeconomy encompasses the production of renewable biological resources and their conversion into food, feed, bio-based products and bioenergy via innovative and efficient technologies and feedstocks come from agriculture, forestry, landscape conservation and side streams from food production. The bioeconomy concept was further upgraded to the Circular Economy concept. The Ellen McArthur Foundation, which is one of the leading promoters of the sustainable society, defines the circular economy as an economy which aims to redefine growth, focusing on positive society-wide benefits. It entails gradually decoupling economic activity from the consumption of finite resources and designing waste out of the system. Underpinned by a transition to renewable energy sources, the circular model builds economic, natural, and social capital. It is based on three principles (Ellen MacArthur Foundation, 2020):

- Design out waste and pollution

- Keep products and materials in use

- Regenerate natural system

\section{BIOREFINERY CONCEPTS}

Lignocellulosic biomass fulfils all of the requirements, and the missing element is the total efficient utilisation of all compounds in the carbon sink. The circular economy is complementary to the renewable character of the bioeconomy and must facilitate the recycling of carbon after efficient uses. One of the possible solutions for this are the biorefineries. The definition of biorefining in the circular economy by the IEA Bioenergy Task 42 (IEA, 2018) is that it is "Sustainable processing of biomass into a portfolio of marketable biobased products (food and feed ingredients, chemicals, materials, fuels, energy, minerals, $\mathrm{CO}_{2}$ ) and bioenergy (fuels, power, heat) «. The concept is presented in Figure 1, while the bio refination of biomass concept is presented in Figure 2 .

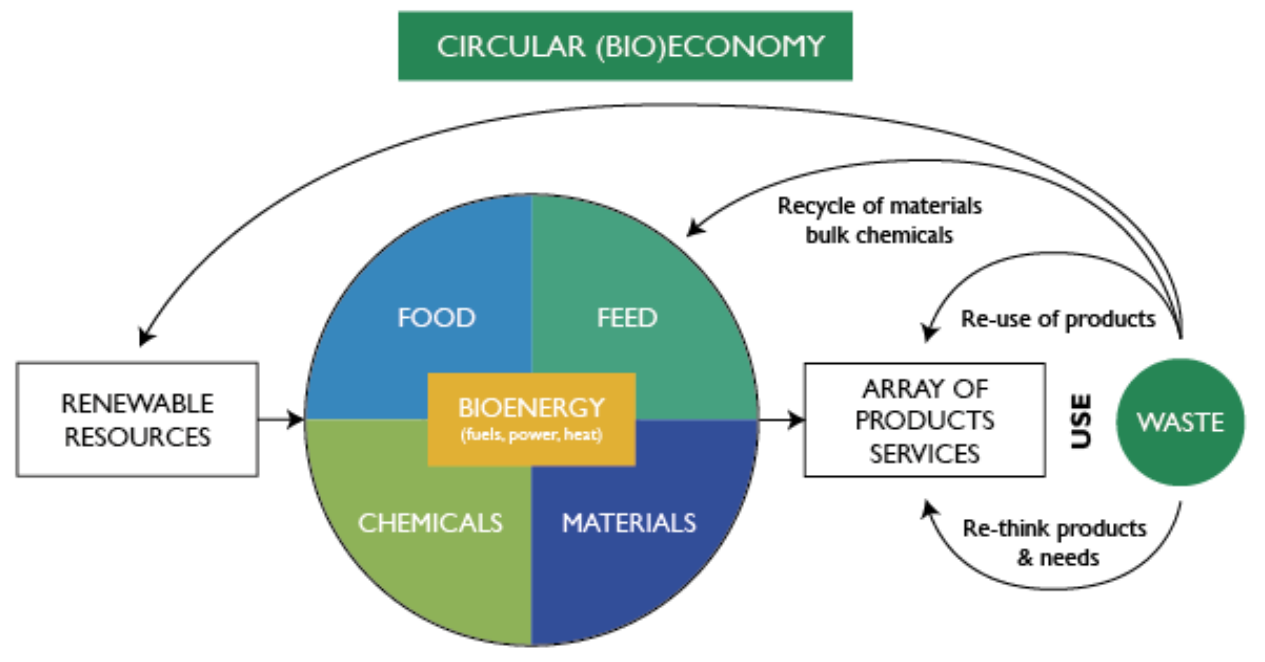

Figure 1: Circular Bioeconomy concept (Adapted from Wenger J. et al, 2018) 


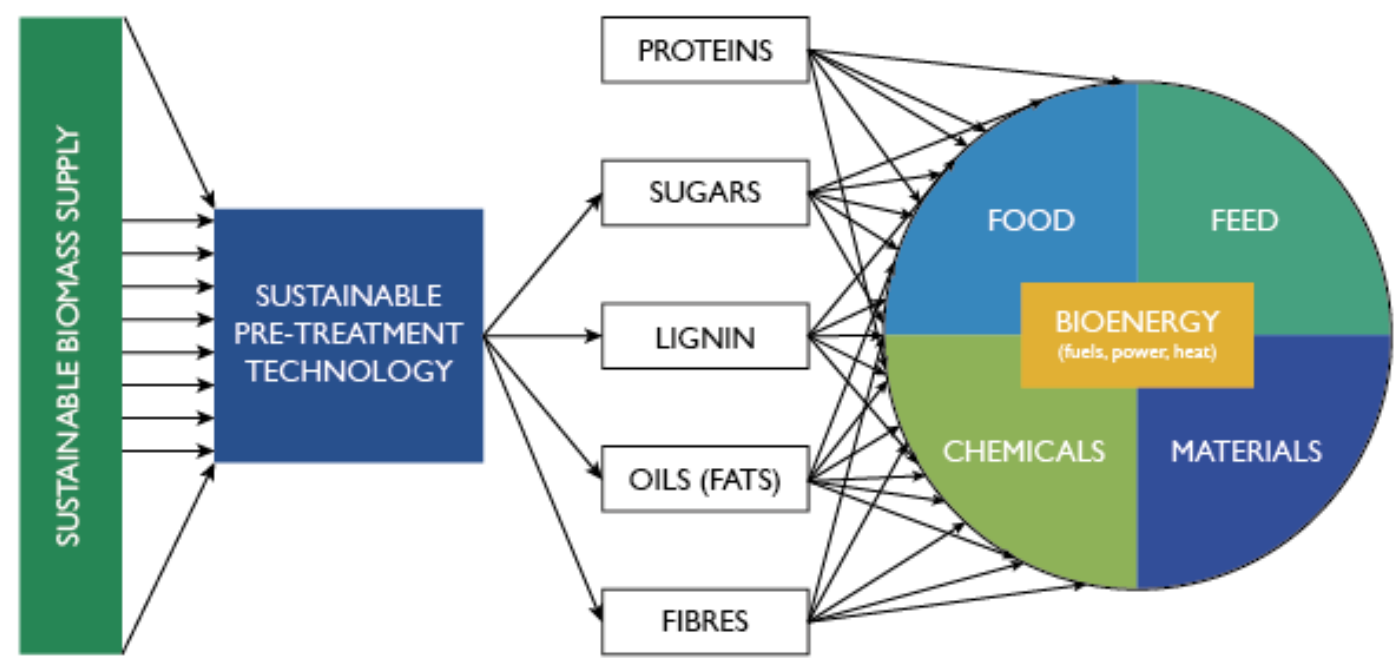

Figure 2: Biomass rafination (Adapted from Wenger J. et al, 2018)

The classification of biorefineries is complex and are sometimes broad and generic, but one which describes the complexity of the system grouping is presented in (Cherubini et al, 2009):

- The lignocellulosic feedstock biorefinery - uses nature dry raw material, such as cellulosecontaining biomass and wastes.

- The whole crop biorefinery - uses raw materials, such as cereals or maize.

- The green biorefinery - uses nature-wet biomasses, such as green grass, alfalfa, clover or immature cereal.

- The two-platform concept biorefinery - includes the sugar and the syngas platforms.

- The conventional biorefinery-based on existing industries, such as the sugar and starch industry.

- The thermochemical biorefinery - based on a mix of several technologies.

- The marine biorefinery - based on marine biomass. 8. The liquid-phase catalytic processing biorefinery - based on the production of functionalised hydrocarbons from biomass-derived intermediates.

- The forest-based biorefinery - based on the full integration of biomass and other feedstocks (including energy), for simultaneous production of pulp, (paper) fibres, chemicals and energy

Due to limitations and scope of this paper, we shall give an overview of the side streams and possible uses of biorefinery products from the lignocellulosic feedstock biorefinery (which also encompasses the forest-based biorefinery). The biochemical and biomaterial side streams and derivates (fibres, hemicellulose, lignin) which will be presented will cover only the packaging sector (thus they can also be used in other industries like pharmaceuticals, cosmetics and food industry).

The lignocellulosic-feedstock biorefinery uses lignocellulosic biomass as feedstock with the advantages of high availability, moderate cost, no direct competition with food and feed production, and has a "good position of conversion products on the traditional Petro-chemical and future biobased product market" (Kamm et al, 2016). The components (mainly cellulose, lignin and hemicellulose) are separated by several available procedures before being further processed into various products and bioenergy; however, certain technologies (e.g., separation, lignin utilisation) still need to be further developed. The pulp and paper industry serves as an example of this specific biorefinery type as it has placed an increasing focus on "value-added coproducts from underutilised streams and waste materials »since the 1980s (De Jong et al, 2015). With its main fibrous products and "value-added coproducts, including, e.g., tall oil, acetic acid, furfural, and lignosulfonates," the pulp and paper industry can also be considered as an early non-foodcrop industrial biorefinery (De Jong et al, 2015). For instance, lignin has mainly been burned as black liquor up until now, and the chemical recovery processes are used for energy (heat, electricity) production; however, lignin is also said to have great potential for use to create products in the future, such as renewable polymers or materials. Further perspectives on lignocellulosic biorefineries can be found in (Hassan et al, 2019), Saini et al (2019), (Konwar et al, 2018) and (de Jong and Gosselink, 2014). 


\section{FIBER (CELLULOSE AND NANOCELLULOSE) APPLICATIONS}

Cellulose $\left[\left(\mathrm{C}_{6} \mathrm{H}_{10} \mathrm{O}_{5}\right) \mathrm{n}\right]$ is an organic compound and the most abundant biopolymer on Earth. It is a complex carbohydrate or polysaccharide consisting of hundreds to thousands of glucose molecules, linked together to form a chain. An overview of cellulose structure can be found in (leoleovich, 2008). The principal commercial use for cellulose is paper manufacturing, where the kraft process is used to separate cellulose from lignin. Cellulose fibres can be also be utilised in the textile industry, while microcrystalline cellulose and powdered cellulose are used as drug fillers and as food thickeners, emulsifiers, and stabilisers. An illustration of fibre-relevant aspects in lignocellulosic-feedstock biorefineries appears in Figure 3, while an in-depth review of the fibre applications can be found in (Wenger et al, 2018).

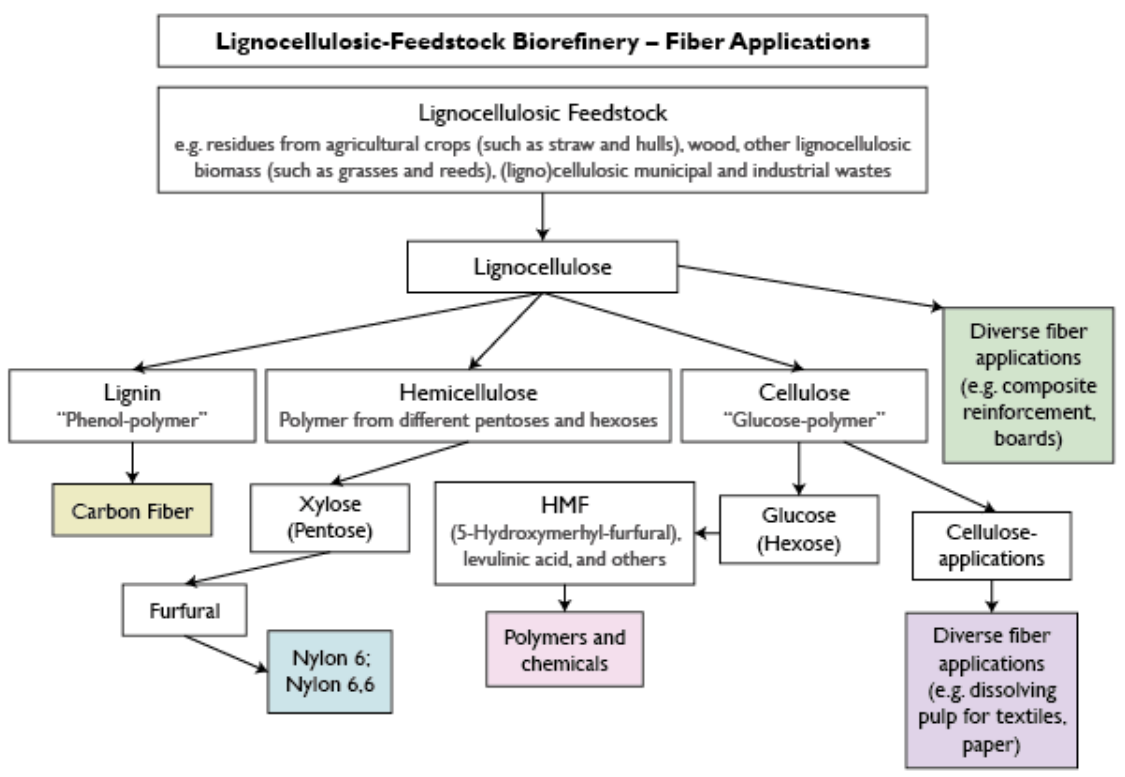

Figure 3: Fibre applications in lignocellulosic-feedstock Biorefinery (Adapted from Wenger J. et al, 2018)

From Figure 3. We can see that regarding cellulose we can take two routes: the bio-chemicals through glucose as a building block for polymer solutions or more fibre-based cellulose applications. The application routed is, of course, dependent on the market value of the selected fibre applications and in Figure 4. a scheme is presented which shows approximate bandwidths and relations between prices and volumes in different applications fields.

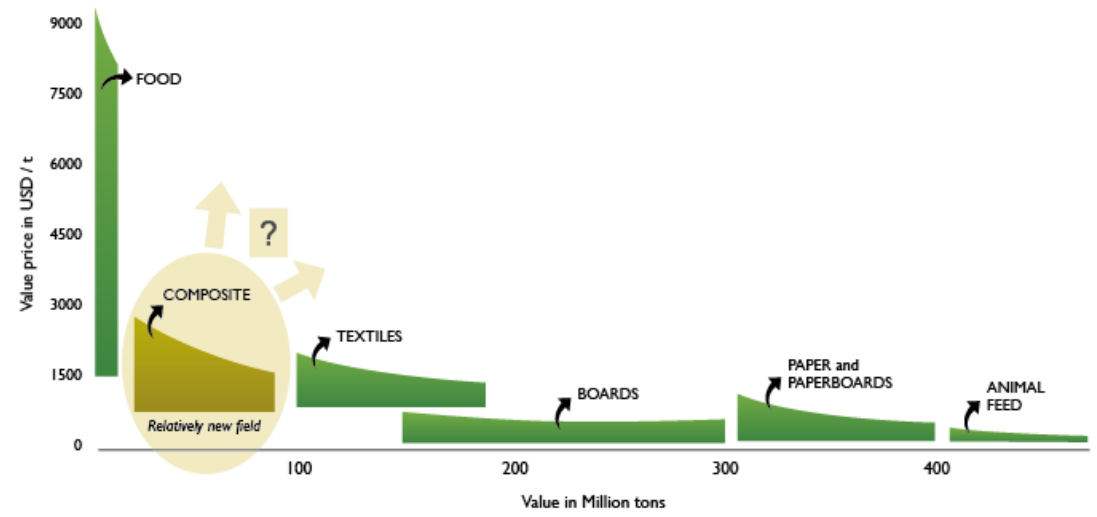

Figure 4: Market value and volumes of fibre-based solutions

From Figure 4. We can see that the highest potential market value has a recently developing filed of composites and technical textiles while the paper and board applications with specialised packaging solutions can mitigate the stagnation of classic printing and writing papers. Solutions which can be 
directly be applied to the packaging via composites and paper and boards are micro-fibrillated cellulose (M.F.C.) and nano-cellulose applications, fibre-based foams and fibre-based composites.

\subsection{Micro-fibrillated cellulose (M.F.C.) and nano-cellulose}

In addition to conventional fibres, micro- and nanoscale cellulose are promising materials. They can be grouped into three main types: micro-fibrillated cellulose (M.F.C.), nanocrystalline cellulose (N.C.C.) and bacterial nano-cellulose (BNC), which can be distinguished according to their dimensions, functions and preparation methods. Table 1, taken from Klemm et al (2011), gives a brief summary of M.F.C., N.C.C. and BNC (sources, formation and average size).

Table 1: Parameters and speed (Klemm, 2011)

\begin{tabular}{|c|c|c|c|}
\hline Type of nanocellulose & $\begin{array}{l}\text { Selected } \\
\text { references and } \\
\text { synonyms }\end{array}$ & Typical sources & Formation and average size \\
\hline $\begin{array}{l}\text { Micro-fibrillated } \\
\text { cellulose (M.F.C.) }\end{array}$ & $\begin{array}{l}\text { Micro-fibrillated } \\
\text { cellulose, } \\
\text { nanofibrils, } \\
\text { nano-fibrillated } \\
\text { cellulose }\end{array}$ & $\begin{array}{l}\text { Wood, sugar } \\
\text { beet, potato } \\
\text { tuber, hemp, } \\
\text { flax, invasive } \\
\text { plants }\end{array}$ & $\begin{array}{l}\text { Delamination of wood pulp by } \\
\text { mechanical pressure before } \\
\text { and after chemical or } \\
\text { enzymatic treatment; diameter } \\
\text { 5-60 nm; length; several } \\
\text { micrometres }\end{array}$ \\
\hline $\begin{array}{l}\text { Nano-crystalline } \\
\text { cellulose (N.C.C.) }\end{array}$ & $\begin{array}{c}\text { Cellulose } \\
\text { nanocrystals, } \\
\text { crystallites, } \\
\text { whiskers, rod- } \\
\text { like cellulose } \\
\text { microcrystals }\end{array}$ & $\begin{array}{l}\text { Wood, cotton, } \\
\text { hemp, flax, } \\
\text { wheat straw, } \\
\text { mulberry bark, } \\
\text { ramie, Avicel, } \\
\text { tunicin, cellulose } \\
\text { from algae and } \\
\text { bacteria }\end{array}$ & $\begin{array}{l}\text { Acid hydrolysis of cellulose } \\
\text { from many sources; } \\
\text { diameter:5-70 nm; length:100- } \\
250 \mathrm{~nm} \text { (from plant cellulose); } \\
10 \mathrm{~nm} \text { to several micrometres } \\
\text { (from the cellulose of } \\
\text { tunicates, algae, bacteria) }\end{array}$ \\
\hline Bacterial nano-cellulose & $\begin{array}{l}\text { Bacterial } \\
\text { cellulose, } \\
\text { microbial } \\
\text { cellulose, bio- } \\
\text { cellulose }\end{array}$ & $\begin{array}{l}\text { Low-molecular- } \\
\text { weight sugars } \\
\text { and alcohols }\end{array}$ & $\begin{array}{c}\text { Bacterial synthesis; diameter } \\
\text { 20-100 nm; different types of } \\
\text { nanofiber networks }\end{array}$ \\
\hline
\end{tabular}

Nano-cellulose has an extensive range of potential applications, with the highest demand for composites (35\% of the total nano-cellulose demand), pulp and paper (15\%), paints, films and coatings (15\%). The use of nanocellulose in packaging applications can be grouped into biocomposites where we blend the nanocellulose with other biopolymers. It can be utilized as an agent for achieving better barrier properties on packaging material with additional active packaging functionalities like antioxidant and aroma-active agents for controlled release. Both multi-functional bio-based composites and tailor-made nano papers have shown improved mechanical properties and excellent functional properties, such as transparency, biodegradability, and specific surface properties to add new functionalities like gas barrier enhancement and heat sealability (Johansson et al, 2012). Nanocelluloses (nanofibers and whiskers) form a remarkable useful group of naturally obtained nanomaterials because of their extraordinary mechanical properties, combining high stiffness and strength with lightweight character. For example, cellulose crystals can exhibit Young's modulus of up to ca. $134 \mathrm{GPa}$ and their tensile strength is expected to be in the range of a few GPa (Nishino et al, 1995). These properties mean that nanocellulosics can be placed at the top of high-performance natural materials. However, to apply it into different biocomposite matrix, optimal material and physical properties need to be achieved for the reinforcement's physical dimension and the nature of the interface between reinforcement and matrix. Very different cellulosic materialsbacterial, microcrystalline, microfibrillated or nanocrystalline-can cause distinctly different reinforcement (Miao and Hamad, 2013). For example in (Lavrič et al, 2020) applications of B.F.C. in the 
paper industry is presented, while many more studies demonstrated the usefulness of N.F.C. and B.F.C. mixture with different bio-based polymers such as chitosan or PLA. (Fernandes et al, 2010; Li et al, 2009; Nakagaito et al, 2009; Okubo et al, 2009), PHB (Zhang et al, 2019) or even bio-based epoxies (Nair et al, 2019) and in so-called nano papers. Nano paper produced by nano fibrillated cellulose is an exciting packaging material due to its high toughness and high effectiveness as an oxygen barrier (Henriksson et al, 2008; Nogi et al, 2009). Other reviews of using nanocellulose in food packaging can be found in (Souza et al, 2020; Ferrer et al 2017; Azeredo et al, 2017; Vilarinho et al, 2018) where they confirmed nanocellulose could contribute to the strength of biocomposite barrier films. Biocomposite films compromised of nano cellulose can effectively resist oxygen permeation, and water vapour and moisture resistance are critical areas of challenge. The barrier properties of interesting for paper and paperboard packaging are usually focused on oxygen, water vapour, and aroma permeability. The aforementioned properties are essential to extend the shelf life of fresh foods as well as for other biodegradable or watersensitive products. For a similar reason, grease resistance and hydrophobicity are of importance for many applications of paper and paperboard packaging and are commonly measured to define the general characteristics and potentialities of new materials (Johansson et al, 2012). Properties of nanocellulose films compared with other polymers can be found in (Nair et al, 2014), while one of the most detailed research on permeability properties of cellulose-based films can be found in (Wang et al, 2018) and the application limits are presented in Figure 5.
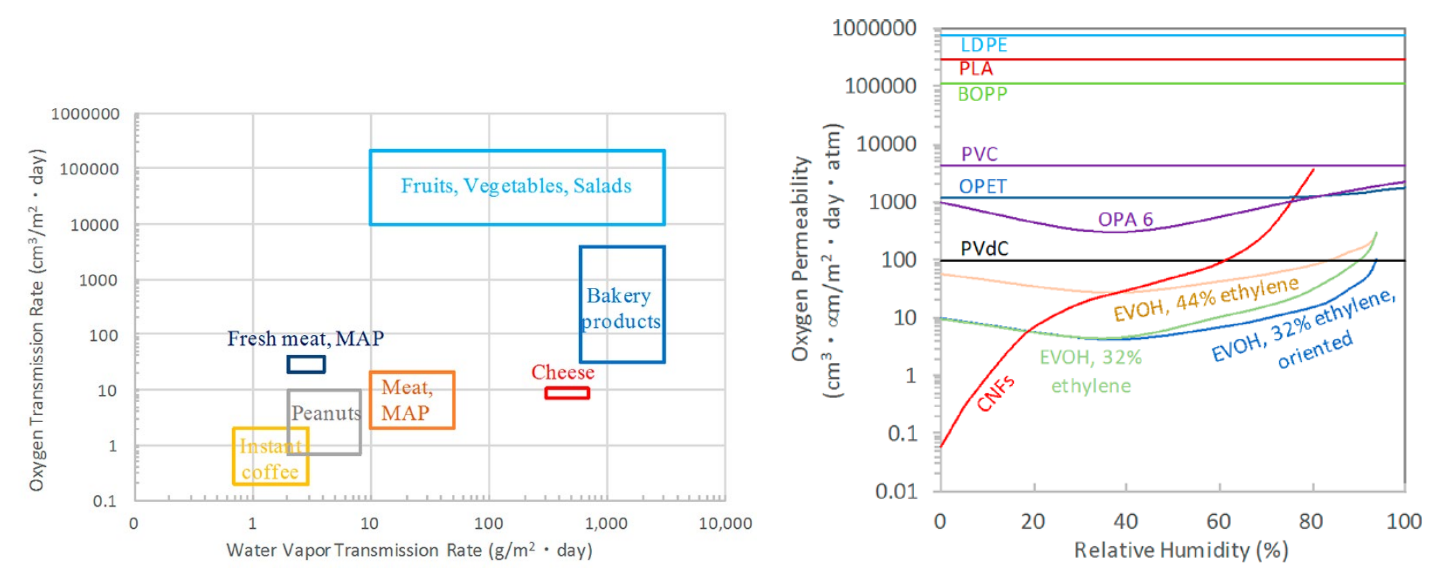

Figure 5: Oxygen Transmission rate of nano cellulosic and commercial polymers (Wang et al, 2018)

In (Brodin et al, 2014), a detailed study is presented on challenges and applications of N.F.C. and M.F.C. in paper coatings. N.F.C. and M.F.C. can as mentioned to be used to surface finish paper and to improve its properties (Havimo et al, 2011; Aulin et al, 2010; Hult et al, 2010; Belbekhouche et al, 2011; Minelli et al, 2010; Syverud and Stenius, 2009; Sothornvit, 2009). Among the different materials, nano-fibrillated cellulose (N.F.C.), has shown exciting barrier properties (Hult et al, 2010; Plackett et al, 2010, Syverud and Stenius, 2009; Sothornvit, 2009) and has been used in different studies related to paper coating (Aulin et al, 2011; Hult et al, 2010; Syverud and Stenius, 2009). In particular, it was shown that carboxymethylated N.F.C. could lead to remarkably high barrier properties, provided that it completely covers the paper surface. Indeed, tested papers coated with a few grams of N.F.C. per square meter showed a decrease of up to six orders of magnitude in air permeability and also showed increased grease resistance (Hult et al, 2010). Of course, the printability of such materials are also essential, and some studies like (Karlovits et al, 2018) showed that the addition of M.F.C. and N.F.C. provided same flexo printing quality as reference papers. Comparison of cellulose and nanocellulose papers were also studied from the morphological, structural and barrier properties by (Djafari et al, 2019). Nevertheless, another promising application is using nanocellulose as an enhancer of starch glues in the corrugated board production where an increase of board production up to $45 \%$ for the BC II was reported by adding nanocellulose based solution (Holtan S., 2020). The market entry into the flexible pouches markets could also be paved by the development of enzymatic fibrillation of cellulose (HefCel) technology which enables refining nanocellulose is in the consistency of $15-25 \%$ when traditional nanocellulose production methods result in 1-3\% consistency. With these properties, it enables production of densely packed structure of nanocellulose films and coatings with outstanding oxygen, grease and mineral oil barrier properties (V.T.T., 2020). An example of this solution is presented in Figure 6, and a commercial solution from Arjowiggins for flexible pouches. 

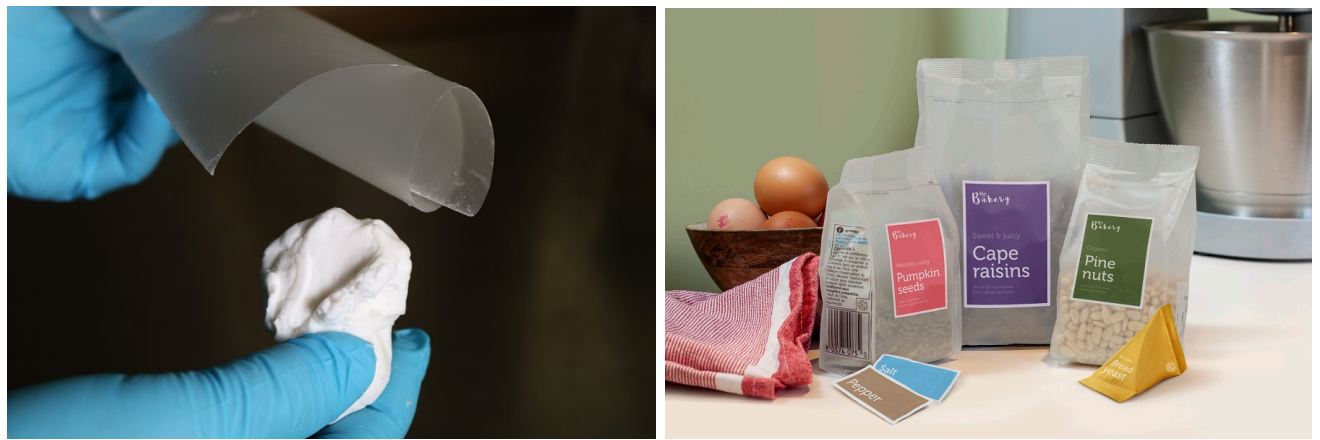

Figure 6: Hefcel nanocellulose (V.T.T.) and nanocellulose based flexible pouches by Arjowiggins

\subsection{Fibre-based cellulose bio foams as packaging material}

One of the most potential technologies beyond paper and board manufacturing is foam forming technology, where water is replaced with aqueous foam. In foam forming technology aqueous foam instead of water is used as a carrier medium in the manufacturing process of fibre-based products. By adding air bubbles in water, the properties of the carrier fluid are changed fundamentally. This new and versatile technology will radically widen the product property window and the variety of raw materials that can be utilised in the manufacturing process. Foam enables utilisation of longer fibres than in traditional water-based process, improved control of web structure and manufacturing of structures having low density compared to paper and board (densities less than $100 \mathrm{~kg} / \mathrm{m}^{3}$ can be obtained) (Pääkkönen, 2020). The current solutions for replacing some forms of EPS packaging are polylactide (PLA) foams, for example, made from corn, and corrugated board and moulded fibre products made from wood pulp; all have benefits and drawbacks. PLA has good water resistance and offers similar performance to EPS, but its price and recycling in current infrastructure hamper its usage. Fiber and fibre moulded solutions, on the other hand, are inferior regarding thermal and cushioning properties. Foamformed cellulose-based materials offer key technical benefits compared with the current alternatives. For example, the foam-forming technology allows short and long fibres to be combined to improve the mechanical performance of the foam, providing better protection. In addition, cellulose fibres can be combined with polymer or biopolymer fibres. Other elements can be incorporated into the foam, for example, a cellulose-PLA foam composite for delicate applications that require a material with excellent cushioning performance. The thermal stability of cellulose-based foams is also better than PLA foams, which means they can be used in hot environments, or to pack products that are still warm from production. Depending on the application, cellulose-based foams can even be produced with existing paper infrastructure to create products such as bio-based board, cushioning materials, nonwoven web, and insulation (Pääkkönen, 2020). An example of a fibre-based foaming structure is presented in Figure 7.

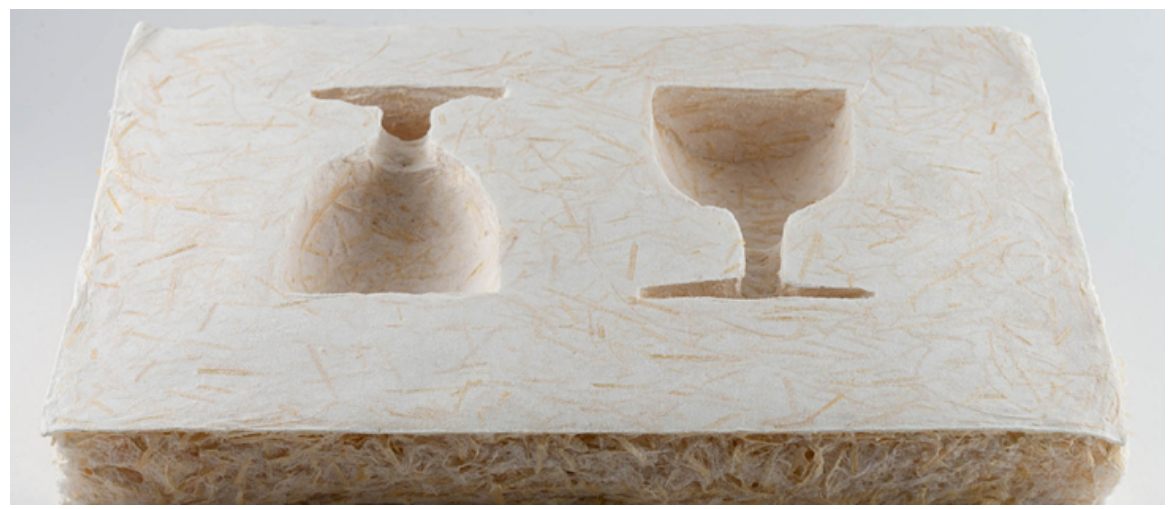

Figure 7: Fibre foam packaging structure (Pääkkönen, 2020).

A study by (Hellen et al, 2013) proved that fibre-based foaming solutions (where fibres and other furnish components are mixed with foam instead of water, and where air content is between 50-70\%) are viable solutions for different applications in packaging. They claim that significant resource savings are expected for foam forming technology in the form of: 
- The most significant advantage through fibre savings

- Less drying energy due to a decreased basis weight

- Chemical costs are lower due to reduced basis weight and improved retention

- Clear improvement in resource-efficiency and benefits in adding value to fibre-based products.

In his PhD study (Al-qararah, 2015) an aqueous foam was used as the carrier phase in the deposition of fibre networks, but on laboratory scales without complications caused by product-specific industrial processes like foam production, wet pressing and drying. His main finding was that in axial mixing, the bubble size and its distribution could be affected by several factors such as the rotation speed, air content and surface tension. The mean bubble size became smaller for natural than regenerated fibres, and the bubble size distribution became narrower for natural fibres. The reasons behind this behaviour were likely to be the rough surfaces of the natural fibres and the related fraction of fine particles, which were absent for regenerated fibres. The microscopic pore structure of foam-formed sheets and water-formed sheets at a roughly equal density were significantly different. The pore size distribution of the foamformed sheets was much more comprehensive than the corresponding distribution of the water-formed sheets. In a paper by (Paunonnen et al, 2018) they enhance the strength of lightweight cellulose fibre foams by combining fines of different length scales and adding polymer (natural rubber). This addition improved the network structure to recover after compression. Forming and subsequent water removal and drying methods have a profound effect on the sheet structure (Timofeev et al, 2016; Haffner et al, 2017). Foam-formed fibre networks can have a much lower density (Madani et al, 2014), improved and tailored pore size distribution (Al-Qararah et al, 2015), and more diverse fibre orientation (Alimadadi and Uesaka, 2016) compared with similar water-formed materials. Foam-formed three- dimensional wood fibre networks (3DFNs) have structural similarities with sheet materials, such as paper. The load-bearing elements in both are the same: fibres, joints, and a connected network.

Paper exhibits three types of deformation: linear and non-linear elastic strain, visco-elastic timedependent recoverable creep, and plastic non-recoverable deformation (Brezinski, 1956; Alava and Niskanen, 2006). Alimadadi and Uesaka (2016) reported the same phases for foam-formed 3DFNs made from pure thermomechanical (T.M.P.) reject pulp. However, the fibre network structure of 3DFNs is very different from that of sheets. The number of bonds a fibre makes with neighbouring fibres at low densities is different from that for thin sheets. 3DFNs also retain their integrity more easily than sheets (Alimadadi and Uesaka, 2016).

Moreover, 3DFNs show a unique and much higher deformation recovery compared with paper and some nonwoven sheets. In addition to the number of bonds (determined by the material density) (Borodulina et al, 2016), the stress and strain distribution in a material is affected by several other factors, such as the fiber length and stiffness. Also, properties like bond compliance and the elastic and viscoelastic creep recovery of foam-formed 3DFNs and extend their use to application areas where highly flexible and elastic materials are preferred.

Besides using fibre-based foams, other solution includes bio-based foams based on starch derivates. In their paper, Su et al (2018) gave an overview of biobased packaging alternatives where different solutions (pure biopolymer foams and fibre-reinforced solutions were presented). The main technical challenges with starch bio-foam are low elasticity, high stiffness, high brittleness, and high water absorption (Shogren et al, 2002; Svagan et al, 2011; Phaodee et al, 2015). In order to improve the strength and water resistance, researchers have added mineral fillers, wood fibres, resin, or coating with wax and other materials (Andersen et al, 1999; Fang and Hanna, 2001). Thanks to their excellent mechanical properties, cellulose fibres can be used as additives to the starch matrix to increase the strength properties, such as tensile strength, stress performance, and toughness (Salgado et al, 2008; Bénézet et al, 2012; Li et al, 2014). Besides that, fibres together with components such as chitosan or natural latex can create synergistic effects to improve further the functional properties of the bio-foam (Kaisangsri et al, 2012; Phaodee et al, 2015). The fibre foaming technology is matured, and the first installation of small production scale facility was launched this year in Finland.

\section{HEMICELLULOSE APPLICATIONS}

Hemicellulose was mainly treated as a waste product in the pulp and paper industry and together with lignin was washed out together with lignin and used as an energy source. Due to is the lower amount in the biomass feedstock (around 20-30\%) and a smaller polymer structure from the cellulose (unlike 
cellulose, hemicellulose consists of shorter chains 500 - 3000 sugar units as opposed to 7000 - 15,000 glucose molecules per polymer), is not a primary choice for reinforcement applications. Nevertheless, it has been investigated in applications like gels and films and was shown to be suitable as in emulsions and stabilisers. Several papers have an overview of the current state of the art on hemicellulose-based hydrogels (Hu et al, 2018), and in Konge et al (2018). In their research (Farhat et al, 2017) have used alkaline treatment for hemicellulose extraction from hardwood pulp and partly delignified switchgrass. Their results showed that loading stress required to break hemicellulose based adhesive connection between two paper surfaces rose after adding 8\% of A.Z.C. crosslinker in the hemicellulose, which increased the adhesive behaviour of the material. The hemicellulose and cellulose modifications (especially wood-based xylan) were routed out for coating and packaging - including films, barrier materials and coating binders - from bleached birch kraft pulp, as well extracted pulp in Laine (2012). The research team had test xylan, for example as binders in pigment - coatings applications for offset grade paper. Good surface strength of coated paper could be demonstrated with butylated and allylated xylan (X-BA2), and it performed almost as well in the tests as the reference latex. The performance of hydroxy propylated xylan (HPX2) was not as good as that of X-BA2. Some development is needed as, e.g., shear viscosities of the coating colours with xylan derivative binders were generally considerably higher than those of the latex colour. In another study by Talja et al (2011), cellulose fatty acid esters were synthesised and characterised from chemical pulps, with different hemicellulose contents. Paper coatings were prepared and analysed. The coatings were hydrophobic, and the barrier properties importantly were found not to vary significantly at all between the cellulose substituents and the degrees of substitution. Water contact angle values were over $90^{\circ}$. Hydrophobicity was also confirmed by low water absorption into the coated boards; the values being similar to those of commercial ones. The best water vapour barrier properties, i.e. the lowest water vapour transmission rates (WVTR) were obtained for the coatings prepared from the palmitoyl esters of the low hemicellulose content pulp cellulose.

One recent research in the utilisation of hemicellulose as a holistic recovery of agricultural residues was presented in (Jahn et al, 2020). In their research, they have tested different sources of hemicellulose (wheat straw, oat husks) and have tested it as a paper additive, flame retardant and floating agent. Their research found that hemicelluloses are also suitable as an additive for increasing the strength of recycling paper. By adding 1 or $2 \mathrm{wt} \%$ hemicellulose the static as well as the dynamic strength increased by more than $10 \%$. The flame-retardant applications were also satisfying, and they achieved in the application of the flame retardants onto fibre-insulating material and to get the same fire protection class as well as a better smouldering performance like conventional flame retardants. This finding can be easily applied to archival boxes and packaging application where fire protection of the packaging container is important. The use as a flotation agent, whereby the digestion method plays an important role, and further research is needed as well that that delignification is not suitable for isolation of foaming agents. One exciting route of reusing materials for a new type of application was described in (Albertson et al, 2010) where they had used the soluble waste from Masonite production. After fractionation, the hemicellulose rich fraction was used to form a cross-linked hydrogel. This hydrogel was further used as a coating on seeds for the temporary inhibition of germination. This concept can be transferred to other coating applications in the print and packaging sector. One direct application of hemicellulose films was made in a dissertation by (Ma, 2018) was screen printed moisture sensor was applied to hemicellulose-based bio-films, and their application for smart packaging was investigated. In this study, the hemicellulose-based barrier coating was applied on to the backside of the commercial S.B.S. board, and on top of it was screen printed moisture sensor. The hemicellulose-based biofilm shows good capability in terms of its mechanical strength and printability to be applied as packaging material. Due to the influence of moisture on barrier properties, the hemicellulose-based biofilm was successfully modified with citric acid. It was found that compared to the sensor printed on uncoated S.B.S. board, the sensor printed on barrier coated S.B.S. board has a significant delay of impedance increase with the increasing R.H. This behaviour shows that the hemicellulose-based barrier coating is capable of blocking out the moisture vapour and can be potentially used for packaging applications. The public research of hemicelluloses as dispersants and texture modifiers in other dispersion applications than foods and cosmetics is however still in early phases. The current status of hemicellulose commercialisation and utilisation is assumed to change for a few reasons. First, there is increased knowledge and (economical) motivation to create biopolymer-based materials and surfactants. Secondly, the availability of non-food hemicelluloses is increasing steadily as the increased valorisation of the non-food biomass and development of the biorefinery concepts. There is commercial and economic interest and demand to make valuable products of all the components of lignocellulose and not just cellulose (Ebringerova and Heinze, 2000). 


\section{LIGNIN APPLICATIONS}

Lignin is not a homogeneous, monodisperse polymer, but rather a complex mixture of polymers that may exhibit a diverse range of molar masses (e.g., polydispersity). There are significant differences in structures between polymers (monomer abundance, interunit linkages), and potential diverse distributions of various functional groups (e.g., primary, secondary, and phenolic hydroxyl and carboxylate groups) between polymer chains. Lignin has been incorporated into many biopolymers, such as starch, protein, cellulose, P.L.A. and PHB, to form bioplastics solutions. Based on the overview of multiple lignin solutions and fibre applications in bioplastics (Yang et al, 2019) conclude that the lignin as reinforcements can produce bioplastics with high performance. Lignin can function as a plasticiser, stabiliser, or bio-compatibiliser in bioplastics, which will produce different properties on bioplastics. Besides, lignin is modified to enhance its miscibility with biopolymers considerably by functionalisation of hydroxyl groups. However, due to its complex structure, the ability to obtain technical lignin of a reduced degree of association is presently a very tough challenge for promoting the use of lignin in bioplastic. Nevertheless, recent research on cellulose-lignin and lignin-containing cellulosic fibre-reinforced bioplastics are desirable and meaningful. The scheme for the possible combination technologies and applications is presented in Figure 8.

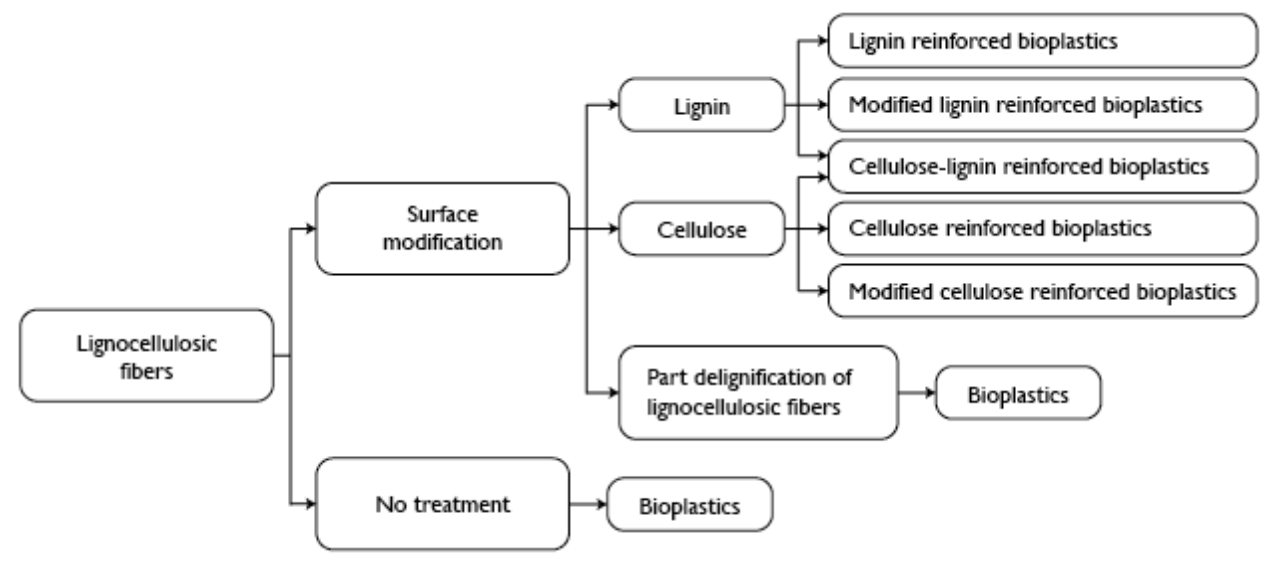

Figure 8: Global scheme of the uses of lignocellulosic fibres and lignin in bioplastics.

Many companies are interested in replacing bisphenol A (commonly known as B.P.A.) with lignin in epoxies, incorporating lignin into polyurethane, and creating biobased foams and coatings. For polyurethane applications, the type, abundance, and accessibility of hydroxyl groups in the lignin are critical. Notably, the relative abundance and distribution of these alcohol groups are strongly dependent on the biomass source and processing history (Alijenad et al, 2019). Kraft softwood lignin has been used to replace 10-30\% (by weight) of the polyol in flexible foam formulations and reported that the developed foam had viscoelastic behaviour similar to the control foams]. The foam produced with $100 \%$ replacement of the polyol with sodium lignosulfonate lignin was dense, brittle, and mechanically weak and was more like a rigid foam than flexible foam. Overall, the prepared foams using kraft lignins and lignosulfonates were reported to have better compressive strength viscoelastic properties], and dimensional and thermal stability relative to the control foams using conventional fossil-derived polyols (Carriço et al, 2016); (Chang et al, 2014) and (Wysocka et al, 2016).

In their work (Tondi et al, 2016) makes formulations, with various lignin/furanic ratios, blowing agents, and catalyst concentrations obtained by the copolymerisation of furanics with the spent liquor from the magnefite wood pulping process. Their research showed that lignin foams could be prepared with various densities as low as $185 \mathrm{~kg} \mathrm{~m}^{-3}$. The lignin foams exhibited typical characteristics of porous materials, i.e., the compression resistances and thermal conductivities were directly proportional to the density. These properties show a similar trend to the previously observed characteristics of tannin foams. These results that these type of lignin-based foams may have the potential to serve as an environmentally-friendly alternative for materials, such as polystyrene and polyurethane. 


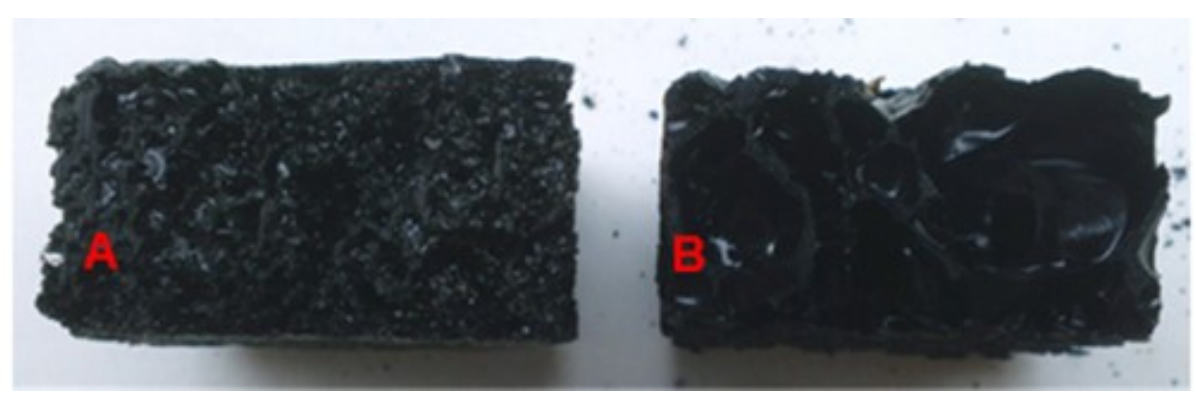

Figure 9: Lignin based foams with and without wood particles (Tondi et al, 2016)

Due to their polyphenolic structure lignins bear several interesting functional properties, such as antioxidant activity. Natural antioxidants are very much looked for in the aim of protection of light or oxygen-sensitive goods and are being used in active packaging. In research conducted by (Domenek et al, 2013) PLA lignin films were prepared by twin-screw extrusion followed by thermo-compression using two different commercial sources of alkali lignins obtained from gramineous plants. Their results show that lignins do not impair the mechanical and barrier performance of the polymer and the plastics processing even allows for the generation of active substances.

In his MSc thesis, Borenius (2019) researched the use of lignin and hemicellulose in dispersions as surfactants and functional materials. During his research that alkali $\mathrm{O}_{2}$ oxidised (LigniOx) lignins showed to have potential as dispersants, especially in carbon black dispersions and to an extent in the titan dioxide dispersions. This type of lignins could be used as dispersants in paint, coating, ink, plastic and other dispersion-related applications. A very detailed study of using lignin in biopolymeric packaging films was done by (Zadeh et al, 2018), where lignin was investigated for use in sustainable biopolymeric packaging film. Alkali lignin and lignosulfonate were added to enzymatically modified soy protein isolate biopolymeric film with different concentrations to improve the film physical and functional properties. As a raw material, alkali lignin (A.L.) and lignosulfonate (L.S.S.) showed significant radical scavenging activity compared to commercial BHT, which carry strong potentials in use for active packaging structure. Films containing A.L. showed strong UV-blocking ability induced by the natural colour of lignin. Mechanical properties and thermal stability of films containing lignin were significantly changed compared to the control films without lignin. This implies that the typical limitations of the biopolymeric film in packagings, such as low mechanical properties and poor thermal properties, may be minimised or solved by utilising lignin and enzymatic treatment, while offering an additional potential in functionality, such as antioxidant activity derived from lignin.

\section{CONCLUSION}

The lignocellulosic biorefinery concept provides future places for packaging material building blocks production. Sustainable and circular uses of bio-based resources demand to meet society needs will be dependent on the production of a variety of products like food, feed, materials, chemicals and energy from limited resources. Nanocellulose and lignin as fillers, reinforcement agents and potential antimicrobial materials open up numerous possibilities in the packaging applications. Nanocellulose already is on the brink of broader commercialisation with numerous applications (mainly around the "old" pulp and paper mills), while hemicellulose and lignin are in the early rising stage of development. The biopolymer composites as it seems are in the ambiguous phase as part of the polymer industry, is pushing the chemical recycling of petroleum-based polymers instead of natural-based ones. The demand from the customers is crucial as this will increase the development of smart bio-based circular packaging solutions. It is up to policymakers and the market to recognise that quality lignocellulosic materials are still widely used for energy production or lower value-added products (commodity papers), and a change has to be made. The success in the specialised markets can open up the necessary demand for scaling up, which can provide products of higher, more efficient volumes of biobased renewable products which do not pollute the environment. Another challenge in areas with decentralised biomass availability (unlike the refurbished pulp and paper mills near large forest areas) is in small scale but flexible biorefineries and logistics optimisation where contemporary I.T. solutions like artificial intelligence can be used. This would thoroughly connect the two fibre worlds (the natural and the digital optic one). 


\section{REFERENCES}

[1] Alava, M., Niskanen, K.: "The physics of paper", Reports on Progress in Physics 69 (3), 669-723, 2006. doi: 10.1088/0034-4885/69/3/R03

[2] Albertsson, A., Voepel, J., Edlund, U., Dahlman, O. and Söderqvist-Lindblad, M.: "Design of Renewable Hydrogel Release Systems from Fiberboard Mill Wastewater", Biomacromolecules 11 (5), 1406-1411, 2010. doi: 10.1021/bm100253e

[3] Alimadadi, M., Uesaka, T.: "3D-oriented fibre networks made by foam forming", Cellulose 23 (1), 661-671, 2016. doi: 10.1007/s10570-015-0811-z

[4] Al-Qararah M. A.: "Aqueous foam as the carrier phase in the deposition of fibre networks", PhD thesis, University of Jyväskylä, 2015.

[5] Al-Qararah, A., Ekman, A., Hjelt, T., Ketoja, J., Kiiskinen, H., Koponen, A., Timonen, J.: “A unique microstructure of the fibre networks deposited from foam-fibre suspensions", Colloids and Surfaces A: Physicochemical and Engineering Aspects 482, 544-553, 2015. doi: 10.1016/j.colsurfa.2015.07.010

[6] Aulin, C., Gällstedt, M., Lindström, T.: "Oxygen and oil barrier properties of microfibrillated cellulose films and coatings", Cellulose 17, 559-574, 2010. doi: 10.1007/s10570-009-9393-y

[7] Aulin, C., Johansson, E., Wågberg, L., Lindström, T.: "Self-organized films from cellulose nanofibrils using the layer-by-layer technique", Biomacromolecules 11 (4), 872-882, 2010. doi: 10.1021/bm100075e

[8] Azeredo, H., Rosa, M., Mattoso, L.: "Nanocellulose in bio-based food packaging applications", Industrial Crops and Products 97, 664-671, 2017. doi: 10.1016/j.indcrop.2016.03.013

[9] Belbekhouche, S., Bras, J., Siqueira, G.: "Water sorption behavior and gas barrier properties of cellulose whiskers and microfibrils films", Carbohydrate Polymers 83 (4), 1740-1748, 2011. doi: 10.1016/j.carbpol.2010.10.036

[10] Bénézet, J. C., Stanojlovic-Davidovic, A., Bergeret, A., Ferry, L., Crespy, A.: "Mechanical and physical properties of expanded starch, reinforced by natural fibres", Industrial Crops and Products 37 (1), 435-440, 2012. doi: 10.1016/j.indcrop.2011.07.001

[11] Borenius, P.: "Lignin and Hemicellulose in Dispersions - as Surfactants and Functional Materials", MSc thesis, Tampere University, 2019.

[12] Borodulina, S., Motamedian, H. R., Kulachenko, A.: "Effect of fibre and bond strength variations on the tensile stiffness and strength of fibre networks", International Jorunal of Solids and Structures 154, 19-32, 2016. doi: 10.1016/j.ijsolstr.2016.12.013

[13] Bouchard, P. "Trees And Carbon Dioxide: What Is The True Connection?", URL: https://medium.com/the-philipendium/trees-and-carbon-dioxide-what-is-the-truth-c7f8c9d12602 (last request: 2020-10-17), 2018.

[14] Brezinski, J. P.: "The creep properties of paper", Tappi Journal 39 (2), 116-128, 1956.

[15] Brodin, F., Gregersen, $\varnothing$., Syverud, K.: "Cellulose nanofibrils: Challenges and possibilities as a paper additive or coating material - A review", Nordic Pulp \& Paper Research Journal 29 (1), 156-166, 2014. doi: 10.3183/npprj-2014-29-01-p156-166

[16] Carriço, C. S., Fraga, T., Pasa, V. M. D.: "Production and characterisation of polyurethane foams from a simple mixture of castor oil, crude glycerol and untreated lignin as bio-based polyols", European Polymer Journal 85, 53-61, 2016. doi: 10.1016/j.eurpolymj.2016.10.012

[17] Chang, L., Sain, M., Kortschot, M.: "Improvement in Compressive Behavior of Alkali-treated Wood Polyurethane Foams", Cellular Polymers 33 (3), 139-158, 2014. doi: 10.1177/026248931403300302

[18] Cherubini, F., Jungmeier, G., Wellisch, M., Willke, T., Skiadas, I., Van Ree, R., de Jong, E.: "Toward a common classification approach for biorefinery systems", Biofuels, Bioproducts and Biorefining 3 (5), 534-546, 2009.

[19] De Jong, E., Gosselink, R.: "Lignocellulose-Based Chemical Products", Bioenergy Research: Advances and Applications, 277-313, 2014. doi: 10.1016/B978-0-444-59561-4.00017-6

[20] De Jong, E., Jungmeier, G.: "Biorefinery Concepts in Comparison to Petrochemical Refineries", Industrial Biorefineries \& White Biotechnology, 3-33, 2015. doi: 10.1016/B978-0-444-63453-5.00001-X

[21] Djafari Petroudy, S., Rahmani, N., Rasooly Garmaroody, E., Rudi, H., Ramezani, O.: "Comparative study of cellulose and lignocellulose nano papers prepared from hardwood pulps: Morphological, structural and barrier properties", International Journal of Biological Macromolecules 135, 512-520, 2019. doi: 10.1016/j.jjbiomac.2019.05.212 
[22] Domenek, S., Louaifi, A., Guinault, A.: "Potential of Lignins as Antioxidant Additive in Active Biodegradable Packaging Materials", Journal of Polymers and the Environment 21, 692-701, 2013. doi: 10.1007/s10924-013-0570-6

[23] Ebringerova A., Heinze T.: "Xylan and xylan derivatives - Biopolymers with valuable properties, 1 Naturally occurring xylans structures, procedures 88 and properties", Macromolecular Rapid Communications 21 (9), 542-556, 2000. doi: 10.1002/1521-3927(20000601)21:9<542::AIDMARC542>3.0.CO;2-7

[24] Ellen McArthur Foundation: "What Is A Circular Economy?" URL: https://www.ellenmacarthurfoundation.org/circular-economy/concept (last request: 2020-10-14), 2020.

[25] EUR-Lex: "Directive 2008/98/EC on waste and repealing certain", URL: https://eurlex.europa.eu/legal-content/EN/TXT/?uri=celex\%3A32008L0098 (last request: 2020-10-14), 2008.

[26] EUR-Lex: "Directive 94/62/EC on packaging and packaging waste", URL: https://eurlex.europa.eu/legal-content/en/TXT/?uri=CELEX:31994L0062 (last request: 2020-10-14), 1994.

[27] FAO: "Forest Product Statistics", URL: http://www.fao.org/forestry/statistics/80938@180723/en/ (last request: 2020-10-18), 2018.

[28] Farhat, W., Venditti, R., Quick, A., Taha, M., Mignard, N., Becquart, F., Ayoub, A.: "Hemicellulose extraction and characterisation for applications in paper coatings and adhesives", Industrial Crops and Products 107, 370-377, 2017. doi: 10.1016/j.indcrop.2017.05.055

[29] Ferrer, A., Pal, L., Hubbe, M.: “Nanocellulose in packaging: Advances in barrier layer technologies", Industrial Crops and Products 95, 574-582, 2017. doi: 10.1016/j.indcrop.2016.11.012

[30] Hassan, S., Williams, G., Jaiswal, A.: "Lignocellulosic Biorefineries in Europe: Current State and Prospects", Trends in Biotechnology 37 (3), 231-234, 2019. doi: 10.1016/j.tibtech.2018.07.002

[31] Havimo, M., Jalomäki, J., Granström, M., Rissanen, A., livanainen, T., Kemell, M., Heikkilä, M., Sipi, M., Kilpeläinen, I.: "Mechanical strength and water resistance of paperboard coated with long chain cellulose esters", Packaging Technology and Science 24 (4), 249-258, 2011. doi: 10.1002/pts.932

[32] Holtan, S.: "Boost Your corrugator productivity with Exilva Microfibrillated cellulose", URL: https://www.exilva.com/blog/boost-your-corrugator-productivity-with-exilva-microfibrillatedcellulose (last request: 2020-10-13), 2020.

[33] Hu, L., Du, M., Zhang, J.: "Hemicellulose-Based Hydrogels Present Status and Application Prospects: A Brief Review", Open Journal of Forestry 08 (01), 15-28, 2018. doi: 10.4236/ojf.2018.81002

[34] Hult, E.-L., lotti, M., Lenes, M.: "Efficient approach to high barrier packaging using microfibrillar cellulose and shellac", Cellulose 17 (3), 575-586, 2010.

[35] Johansson, C., Bras, J., Mondragon, I., Nechita, P., Plackett, D., Šimon, P., Svetec, D. G., Virtanen, S., Baschetti, M. G., Breen, C., Clegg, F., Aucejo, S.: "Renewable fibres and bio-based materials for packaging applications - A review of recent developments", Bioresources 7 (2), 2506-2552, 2012. doi: 10.15376/biores.7.2.2506-2552

[36] Kaisangsri, N., Kerdchoechuen, O., Laohakunjit, N.: "Biodegradable foam tray from cassava starch blended with natural fiber and chitosan", Industrial Crops and Products 37 (1), 542-546, 2012. doi: 10.1016/j.indcrop.2011.07.034

[37] Kamm, B., Gruber, P. R., Kamm, M.: "Biorefineries-Industrial Processes and Products", In: Ullmann's Encyclopedia of Industrial Chemistry, (Wiley-VCH Verlag, Berlin, 2016.), pages 1-38. doi: 10.1002/14356007.104_101.pub2

[38] Karlovits, I., Lavrič, G., Pleša, T., Kavčič, U.: "The influence of M.F.C. and N.F.C. addition in an uncoated paper on flexography optical print quality", Paper technology and industry 59 (1), 14-18, 2018.

[39] Kong, W., Dai, Q., Gao, C., Ren, J., Liu, C., Sun, R.: “Hemicellulose-Based Hydrogels and Their Potential Application”, In: Polymer Gels. Gels Horizons: From Science to Smart Materials, (Springer, Singapore, 2018). doi: 10.1007/978-981-10-6086-1_3

[40] Konwar,L. J., Mikkola, J.-P., Bordoloi, N., Saikia, R., Chutia, R. S., Kataki, R.: "Sidestreams From Bioenergy and Biorefinery Complexes as a Resource for Circular Bioeconomy", In: Waste Biorefinery, (Elsevier, Amsterdam, 2018.), pages 85-125, doi: 10.1016/B978-0-444-63992-9.00003-3

[41] Lavrič, G., Medvešček, D., Skočaj, M.: "Papermaking properties of bacterial nanocellulose produced from mother of vinegar, a waste product after classical vinegar production", Tappi journal 19 (4), 197-203, 2020. doi: 10.32964/TJ19.4.197 
[42] Li, F., Guan, K., Liu, P., Li, G., Li, J.: "Ingredient of biomass packaging material and compare study on cushion properties", International Journal of Polymer Science 2014, 2014. doi: 10.1155/2014/146509

[43] Madani, A., Zeinoddini, S., Varahmi, S., Turnbull, H., Phillion, A. B., Olson, J. A., Martinez, D. M.: "Ultra-lightweight paper foams: Processing and properties", Cellulose 21 (3), 2023-2031, 2014. doi: 10.1007/s10570-014-0197-3

[44] Miao, C., Hamad, W. Y.: "Cellulose reinforced polymer composites and nanocomposites: a critical review", Cellulose 20, 2221-2262, 2013. doi: 10.1007/s10570-013-0007-3

[45] [45] Nair, S., Dartiailh, C., Levin, D. Yan, N.: "Highly Toughened and Transparent Biobased Epoxy Composites Reinforced with Cellulose Nanofibrils", Polymers 11 (4), 612, 2019. doi: 10.3390/polym11040612

[46] Nair, S. S., Zhu, J., Deng, Y., Ragauskas, A. J.: "High-performance green barriers based on nanocellulose", Sustainable Chemical Processes 2 (23), 2014. doi: 10.1186/s40508-014-0023-0

[47] Packaging Insights: "V.T.T. Develops Lightweight 100\% Bio-Based Stand-Up Pouches", URL: https://www.packaginginsights.com/news/VTT-Develops-Lightweight-100-Bio-Based-Stand-UpPouches.html (last request: 2020-10-18), 2017.

[48] Pääkkönen, E.: “Bio-Based Packaging”, URL: https://makingoftomorrow.com/bio-based-packaging/ (last request: 2020-10-16), 2020.

[49] Phaodee, P., Tangjaroensirirat, N., Sakdaronnarong, C.: "Biobased polystyrene foam-like material from crosslinked cassava starch and nanocellulose from sugarcane bagasse", BioResources 10 (1), 348-368, 2015.

[50] Pira, S.: "Strategic Forecasts For Global Packaging To 2024 - Smithers", URL: https://www.smithers.com/resources/2020/mar/smithers-forecasts-global-packaging-market-togrow (last request: 2020-10-12), 2020.

[51] Ruoxi, M.: "Screen Printed Moisture Sensor On Barrier Coated S.B.S. Board: The Characterisations of the Hemicellulose-Based Biofilms and Their Applications for Smart Packaging", PhD thesis, Western Michigan University, 2018.

[52] Saini J. K., Gupta, R., Hemansi, Verma, A., Gaur, P., Saini, R., Shukla. R., Kuhad, R. C. "Integrated Lignocellulosic Biorefinery for Sustainable Bio-Based Economy", In: Sustainable Approaches for Biofuels Production Technologies, (Springer, Cham, 2019.), doi: 10.1007/978-3-319-94797-6_2

[53] Salgado, P. R., Schmidt, V. C., Molina Ortiz, S. E., Mauri, A. N., Laurindo, J. B.: "Biodegradable foams based on cassava starch, sunflower proteins and cellulose fibers obtained by a baking process", Journal of Food Engineering 85 (3), 435-443, 2008. doi: 10.1016/j.jfoodeng.2007.08.005

[54] Sothornvit, R.: "Effect of hydroxypropyl methylcellulose and lipid on mechanical properties and water vapor permeability of coated paper", Food Research International 42 (2), 307-311, 2009. doi: 10.1016/j.foodres.2008.12.003

[55] Souza, E., Gottschalk, L., Freitas-Silva, O.: “Overview of Nanocellulose in Food Packaging", Recent Patents on Food, Nutrition \& Agriculture, 11 (2), 154-167, 2019. doi: 10.2174/2212798410666190715153715

[56] [56] Syverud K., Stenius, P.: "Strength and barrier properties of MFC films", Cellulose 19, 75-85, 2009. doi: 10.1021/bm700624p

[57] Talja, R. A., Kulomaa, T. P. S., Labafzadeh, S., Kyllönen, L. E., King, A. W. T., Kilpeläinen, I., PoppiusLevlin, K.: "Cellulose esters from birch kraft pulp - new biomaterials for barrier coating", Proceedings of 16th International Symposium on Wood, Fibre and Pulping Chemistry (Tianjin, China, 2011), pages 1394-1398.

[58] Timofeev, O., Jetsu, P., Kiiskinen, H., Keränen, J. T.: "Drying of foam-formed mats from virgin pine fibres", Drying Technology 34 (10), 1210-1218, 2016. doi: 10.1080/07373937.2015.1103254

[59] Tondi, G., Link, M., Kolbitsch, C., Gavino, J., Luckeneder, P., Petutschnigg, A., Herchl, R., Van Doorslaer, C.: "Lignin-based foams: Production process and characterisation", BioResources 11 (2), 2972-2986, 2016.

[60] Vilarinho, F., Sanches Silva, A., Vaz, M. F., \& Farinha, J. P.: "Nanocellulose in green food packaging", Critical reviews in food science and nutrition 58 (9), 1526-1537, 2018. doi: 10.1080/10408398.2016.1270254

[61] Wang, J., Gardner, D. J., Stark, N. M., Bousfield, D. W., Tajvidi, M., Cai, Z.: "Moisture and Oxygen Barrier Properties of Cellulose Nanomaterial-Based Films", ACS Sustainable Chemistry \& Engineering 6 (1), 49-70, 2017. doi: 10.1021/acssuschemeng.7b03523 
[62] Wenger, J., Stern, T., Schöggl, J., van Ree, R., De Corato, U., De Bari, I., Bell, G., Stichnothe, H.: "Natural Fibers And Fiber-Based Materials In Biorefineries Status Report 2018", URL: http://task42.ieabioenergy.com/wp-content/uploads/2018/12/IEA-Bioenergy-Task42-FibresReport_FINAL_181214JW.pdf (last request: 2020-10-12), 2018.

[63] W.W.F.: "Pulp and Paper", URL: https://www.worldwildlife.org/industries/pulp-and-paper (last request: 2020-10-15), 2020.

[64] Wysocka, K., Szymona, K., McDonald, A. G., Mamiński, M. Ł.: "Characterisation of Thermal and Mechanical Properties of Lignosulfonate- and Hydrolyzed Lignosulfonate-based Polyurethane Foams", BioResources, 11, 7355-7364, 2016.

[65] Yang, J., Ching, Y. C., Chuah, H. C.: "Applications of Lignocellulosic Fibers and Lignin in Bioplastics: A Review", Polymers 11 (5), 751, 2019. doi: 10.3390/polym11050751

[66] Zadeh, E., O'Keefe, S., Kim, Y.: "Utilization of Lignin in Biopolymeric Packaging Films", A.C.S. Omega 3 (7), 7388-7398, 2018. doi: 10.1021/acsomega.7b01341

[67] Zhang, B., Huang, C., Zhao, H., Wang, J., Yin, C., Zhang, L., Zhao, Y.: "Effects of Cellulose Nanocrystals and Cellulose Nanofibers on the Structure and Properties of Polyhydroxybutyrate Nanocomposites", Polymers 11 (12), 2063, 2019. doi: 10.3390/polym11122063

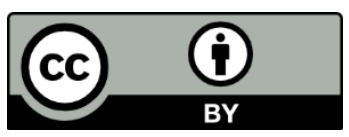

(C) 2020 Authors. Published by the University of Novi Sad, Faculty of Technical Sciences, Department of Graphic Engineering and Design. This article is an open access article distributed under the terms and conditions of the Creative Commons Attribution license 3.0 Serbia (http://creativecommons.org/licenses/by/3.0/rs/). 